\title{
An experimental study on the combined effects of $n$-hexane and toluene on the peripheral nerve of the rat
}

\author{
Y TAKEUCHI, Y ONO, AND N HISANAGA \\ From the Department of Hygiene, Nagoya University School of Medicine, Showa-ku, Nagoya, Japan
}

ABSTRACT An electrophysiological study was undertaken to determine whether toluene affected the neurotoxicity of $n$-hexane. Separate groups of eight rats were exposed to $1000 \mathrm{ppm} n$-hexane, $1000 \mathrm{ppm}$ toluene, $1000 \mathrm{ppm} n$-hexane plus $1000 \mathrm{ppm}$ toluene, or fresh air in an exposure chamber for 12 hours a day for 16 weeks. The body weight, MCV, DL, MNCVs were measured before exposure; after four, eight, 12, and 16 weeks' exposure; and four weeks after exposure was discontinued.

Exposure to $1000 \mathrm{ppm} n$-hexane considerably impaired the function of the peripheral nerve, but exposure to a mixture of $1000 \mathrm{ppm} n$-hexane plus $1000 \mathrm{ppm}$ toluene resulted in only slight impairment; $1000 \mathrm{ppm}$ toluene had little effect. These results strongly suggest that toluene decreases the toxic effects of $n$-hexane on the peripheral nerve.

Hydrocarbon compounds are widely used as organic solvents in industry, and since many workers are chronically exposed to mixtures of solvent vapours it is important to study the effects on health of such exposure.

$n$-Hexane is one of the major constituents of many petroleum solvents and of many artificially mixed solvents. It is now well known to be neurotoxic, and many cases of polyneuropathy have been reported to be attributed to $n$-hexane in solvent mixtures. For example, vinyl sandal manufacturers who suffered from polyneuropathy used adhesives containing commercial hexane and toluene, ${ }^{1}$ and workers at a furniture factory in the Bronx also suffered from polyneuropathy when exposed to solvents that contained among others acetone and $n$-hexane and its isomers. ${ }^{2} 3$

A pronounced atrophy of the muscles of the extremities has been found in a patient who sniffed glue, the distillate of which contained $n$-hexane and its isomers, toluene and ethyl acetate, ${ }^{4}$ while patients sniffing solvents containing $n$-hexane, benzine fraction, toluene, ethyl acetate, and methyl ethyl ketone (MEK) have also developed polyneuropathy. ${ }^{5}$ In addition to these clinical observations, experi-

Received 6 February 1980

Accepted 16 April 1980 mental evidence has shown that MEK may potentiate the neurotoxicity of $n$-hexane ${ }^{5}$ and methylbutyl ketone, ${ }^{615}$ although not itself particularly toxic to the peripheral nerve.

The present study has been carried out to determine whether or not toluene may affect the neurotoxicity of $n$-hexane.

\section{Materials and methods}

Thirty-two Wistar strain male rats (mean body weight $310 \mathrm{~g}, \mathrm{SD} \pm 18 \mathrm{~g}$ ) were divided into four groups of eight, and the separate groups were exposed to $1000 \mathrm{ppm} n$-hexane, $1000 \mathrm{ppm}$ toluene, $1000 \mathrm{ppm} n$-hexane plus $1000 \mathrm{ppm}$ toluene, or fresh air in an exposure chamber ${ }^{7}$ for 12 hours a day for 16 weeks (fig 1). Food and water were provided freely. The temperature and the relative humidity in the chamber fluctuated from $23.5^{\circ} \mathrm{C}$ to $24.5^{\circ} \mathrm{C}$ and $40-60 \%$. The $n$-hexane and toluene used were more than $99 \%$ pure, and the concentrations of vapour in the chamber were measured daily by gas chromatography. The measured concentrations were $1049 \pm 87 \mathrm{ppm}$ of $n$-hexane, $1075 \pm 88 \mathrm{ppm}$ of toluene, and $1063 \pm 77 \mathrm{ppm}$ of $n$-hexane plus $1045 \pm 102 \mathrm{ppm}$ of toluene (mean $\pm \mathrm{SD}$, for 16 weeks).

Peripheral nerve conduction velocity was measured 

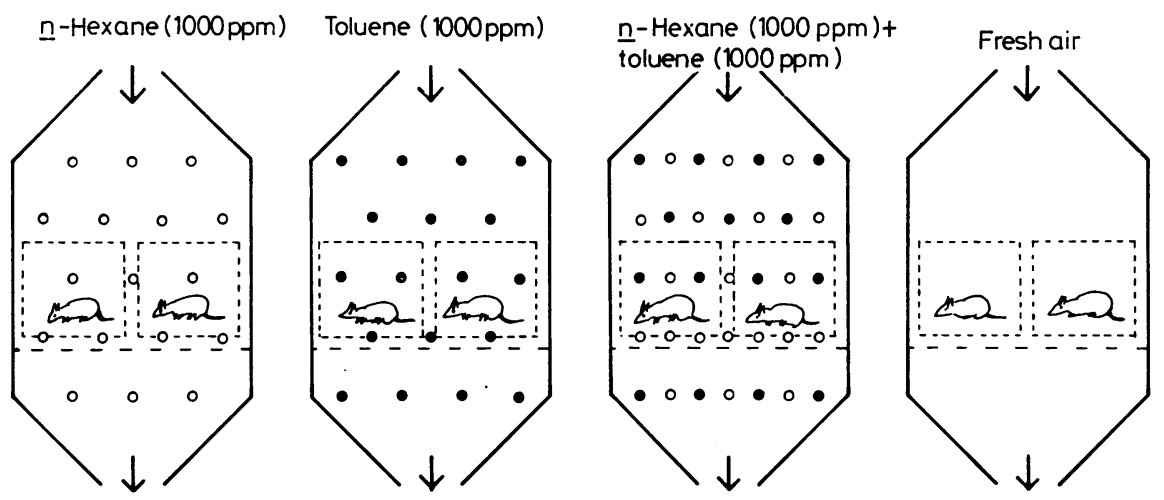

Fig 1 Exposure programme; each group of eight rats was exposed to $n$-hexane, toluene, and n-hexane plus toluene respectively 12 hours a day for 16 weeks.

in the nerve of the rat's tail. The rat was wrapped in a towel to keep it immobilised without anaesthesia and laid on its back to allow electrodes to be inserted in the tail at the points shown in fig 2 . The electrode was a stainless steel needle, $0.34 \mathrm{~mm}$ in diameter and about $15 \mathrm{~mm}$ long. Electrode A (fig 2) was located $3 \mathrm{~cm}$ distal from the anus; the distance between electrodes $A$ and $B$ was $7-10 \mathrm{~cm}$; the distance between $\mathrm{B}$ and $\mathrm{C}$ was kept constant at $5 \mathrm{~cm}$, electrode $\mathrm{C}$ being located $3-4 \mathrm{~cm}$ proximal to the end of the tail. After the insertion of the electrodes, the tail was immersed in a paraffin bath in which the temperature was maintained between 37 and $38^{\circ} \mathrm{C}$. The conduction velocity of the tail nerve was measured after at least four minutes after immersion, and the measurement was finished within 20 minutes of immersion, as in the previous experiments. ${ }^{89}$ The tail nerve was stimulated by a square pulse of

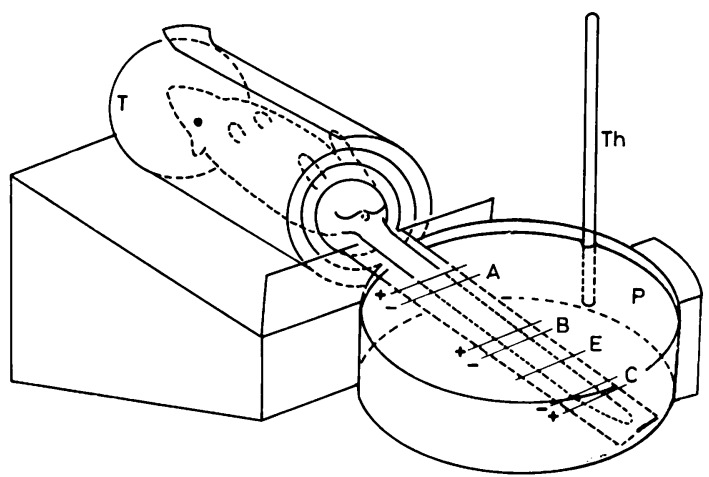

Fig 2 Sketch of method of measuring nerve conduction velocity of rat's tail. $A, B, C=$ stimulating and recording electrodes; $E=$ earth; $T=$ towel; $P=$ liquid Paraffin; $T h=$ thermometer.
$0.3 \mathrm{msec}$ duration, $2 \mathrm{c} / \mathrm{s}$ and supramaximal strength with an electrostimulator (SEN-7103) with an isolating unit (Nihon Koden); the biopotentials were observed with an Addscope (ATAC-350, Nihon Koden). One hundred nerve impulses were observed and summated to obtain the following indices: motor nerve conduction velocity (MCV) $=\mathrm{AB} /$ latency time $(\mathrm{AC}-\mathrm{BC})$; motor distal latency $(\mathrm{DL})=$ latency time (BC); mixed nerve conduction velocity $(\mathrm{MNCV})(\mathrm{CA})$ (total part) $=\mathrm{CA} /$ latency time (CA); MNCV (CB) (distal part) = CB/latency time (CB); MNCV (BA) (proximal part) = BA/ latency time (CA-CB). The body weight, MCV, DL, and MNCV (CA, CB, and BA) were all measured before exposure; after four, eight, 12, and 16 weeks' exposure; and four weeks after exposure was discontinued. The relations between the total dose of $n$-hexane (ppm $\times$ hour) and the effect (percentage of measured value in the control group) were calculated for each exposed group, and for a group previously exposed to $3000 \mathrm{ppm} n$-hexane. ${ }^{9}$

\section{Results}

The changes in body weight, MCV, and DL are shown in fig 3. The body weights of the animals exposed to $1000 \mathrm{ppm} n$-hexane and $1000 \mathrm{ppm}$ toluene groups were slightly less than those of the controls, but those of the mixed exposure group did not show any significant differences from the controls throughout the experiment. The MCVs of the $n$-hexane group were considerably lower than those of the control; the MCV of the toluene group became slightly lower after eight weeks' exposure.

In the group with mixed exposure, MCVs were slightly lower than those of the control; four weeks after exposure was discontinued, however, there was no significant difference. The MCVs of the mixed 

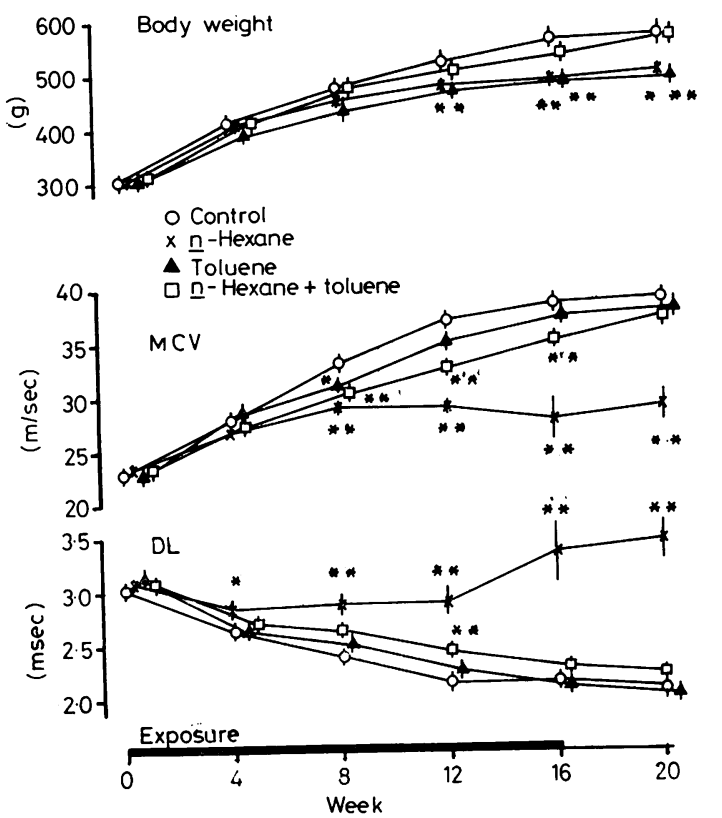

Fig 3 Changes in body weight, motor nerve conduction velocity $(M C V)$, and distal latency $(D L)($ Mean $\pm S E)$. Significance level: ${ }^{*} p<0.05,{ }^{* *} p<0.01$.

exposure group were significantly greater than those of the $n$-hexane group.

The DLs of the $n$-hexane group were significantly greater than the control after four weeks' exposure and became greater still as exposure continued.

The DLs of the toluene group did not show any significant differences from those of the control throughout the experiment. In the mixed exposure group, DLs were slightly greater than those of the control, and significantly lower than those of the $n$-hexane group.

Changes in MNCVs are shown in fig 4. In the distal part of the tail (CB), MNCVs were significantly lower in the $n$-hexane group than in the control after four weeks' exposure, becoming lower still with continuing exposure. MNCVs in the proximal part of the tail (BA) and in the whole tail (CA) were also significantly lower in the $n$-hexane group than in the controls from eight weeks' exposure to the end of the experiment. The MNCVs of the toluene group showed no significant differences from the controls throughout the experiment except for MNCV (CB) after eight weeks' exposure. In the mixed exposure group, MNCVs were slightly lower than in the controls, but significantly higher than in the $n$-hexane group. A summary of the significant differences between the groups is given in fig 5 . These results show that the function of the peripheral nerve is
Control

$x$ n-Hexane

$\Delta$ Toluene

므-Hexane + toluene
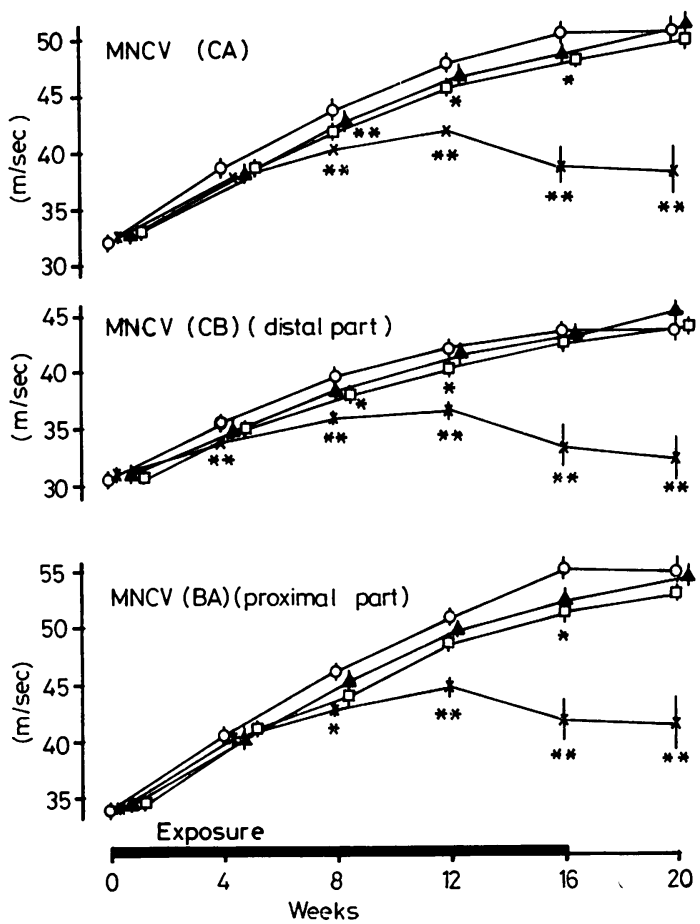

Fig 4 Changes in mixed nerve conduction velocity $(M N C V s)(M e a n \pm S E)$. Significance level: ${ }^{*} p<0.05$ $* * p<0.01$.

considerably impaired in the $1000 \mathrm{ppm} n$-hexane group, slightly impaired in the mixed exposure group, and almost unaffected in the toluene group. Thus toluene appears to decrease the toxicity of $n$-hexane on the peripheral nerve.

The linear relations between the dose and the effect of $n$-hexane on body weight, MCV, and DL are shown in fig 6.

The slopes of the regression lines in the $1000 \mathrm{ppm}$ $n$-hexane group were steeper than those in the mixed exposure group and in the group of animals previously exposed to $3000 \mathrm{ppm} n$-hexane. ${ }^{9}$ The relations between the dose of $n$-hexane and MNCVs are shown in fig 7. They were linear up to 12 weeks' exposure, but the values after 16 weeks' exposure deviated downward from the regression lines in both the $1000 \mathrm{ppm} n$-hexane and $3000 \mathrm{ppm} n$-hexane groups. The slopes of the regression lines in the 1000 ppm $n$-hexane group were steeper than those in the mixed exposure group and the $3000 \mathrm{ppm} n$-hexane group; the slopes in the mixed exposure group were 


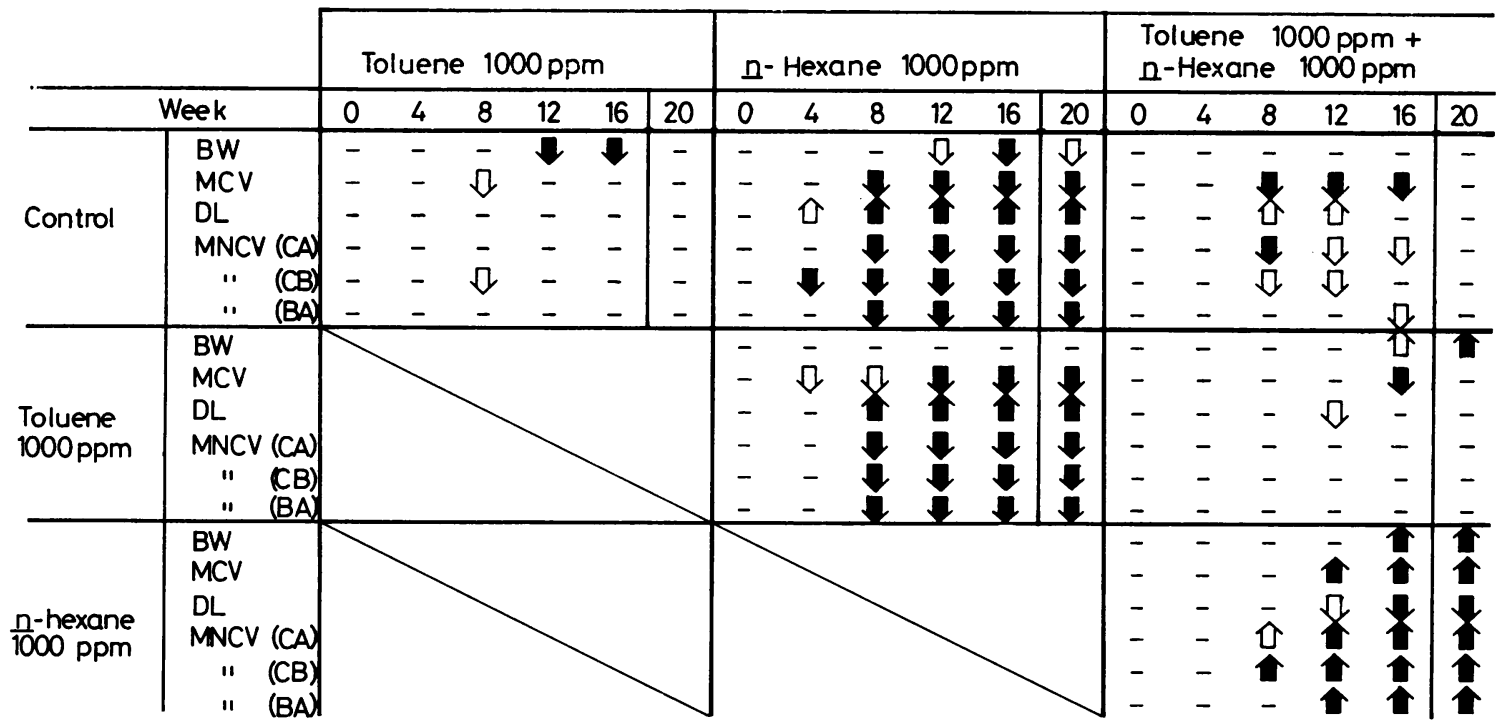

$B W=$ body weight $: M C V=$ motor nerve conduction velocity $: D L=$ distal latency: $M N C V=\underset{\text { melocity }}{\text { velve conduction }}$ Arrows show statistically significant levels and directions : $p<0.05 \square p<0.01$

Fig 5 Significant differences between each two groups in measured values.

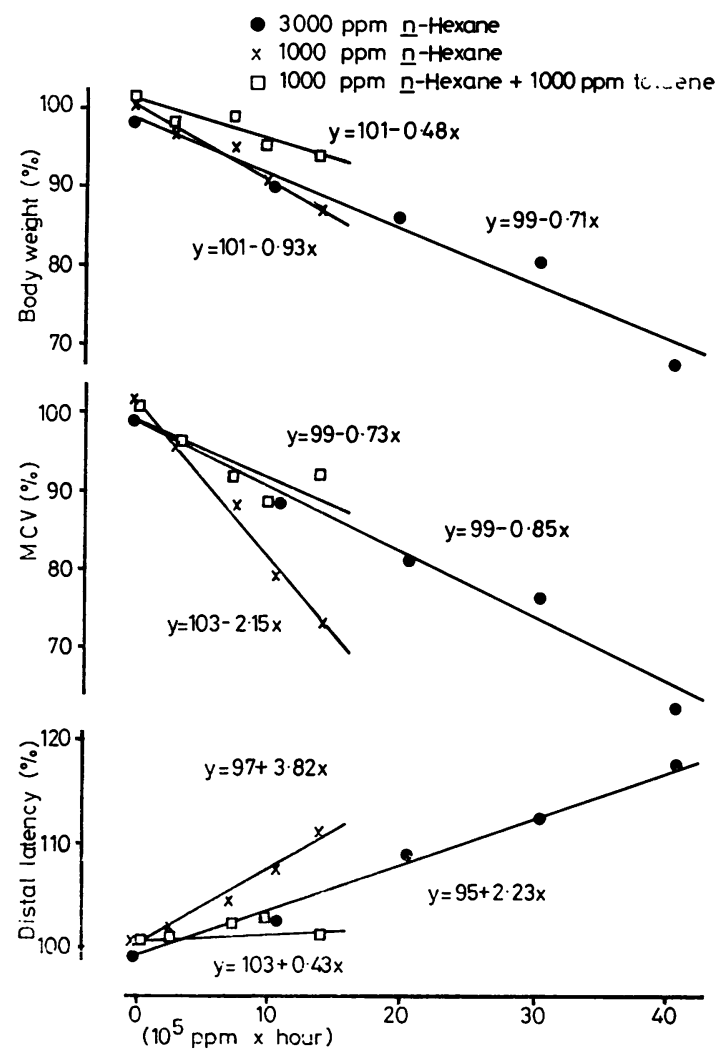

Fig 6 Relations between dose of $n$-hexane $(\mathrm{ppm} \times \mathrm{hr})$ and effect (percentage of measured value per the control). almost similar to those in the $3000 \mathrm{ppm} n$-hexane group.

\section{Discussion}

In the group of animals exposed to $1000 \mathrm{ppm}$ $n$-hexane impairments of DL and MNCV (CB) were detected after four weeks' exposure; with continuing exposure the changes became even more pronounced, although the clinical signs of neuropathy were not found in any groups throughout the experiment. These results showed that the present electrophysiological method was much more sensitive in detecting early functional impairment of the peripheral nerve in $n$-hexane poisoning than clinical signs of neuropathy, and that this method was convenient to follow up the continuous functional changes of $n$-hexane neuropathy in the same rats. ${ }^{510}$

The mixed exposure of $1000 \mathrm{ppm} n$-hexane plus $1000 \mathrm{ppm}$ toluene did not impair the peripheral nerve as greatly as $1000 \mathrm{ppm} n$-hexane given alone, suggesting that toluene protects against the neurotoxic effect of $n$-hexane in mixed exposure. $n$-Hexane per se is considered to have no particular neurotoxicity, but to be metabolised in vivo into neurotoxic substances. ${ }^{31112}$ The co-administration of toluene and trichloroethylene is reported to inhibit their oxidation, ${ }^{13}$ while the co-exposure of toluene and benzene is reported to reduce the urinary excretion of phenol and to inhibit leucocyte depletion. ${ }^{14}$

These reports suggest that toluene may inhibit the 

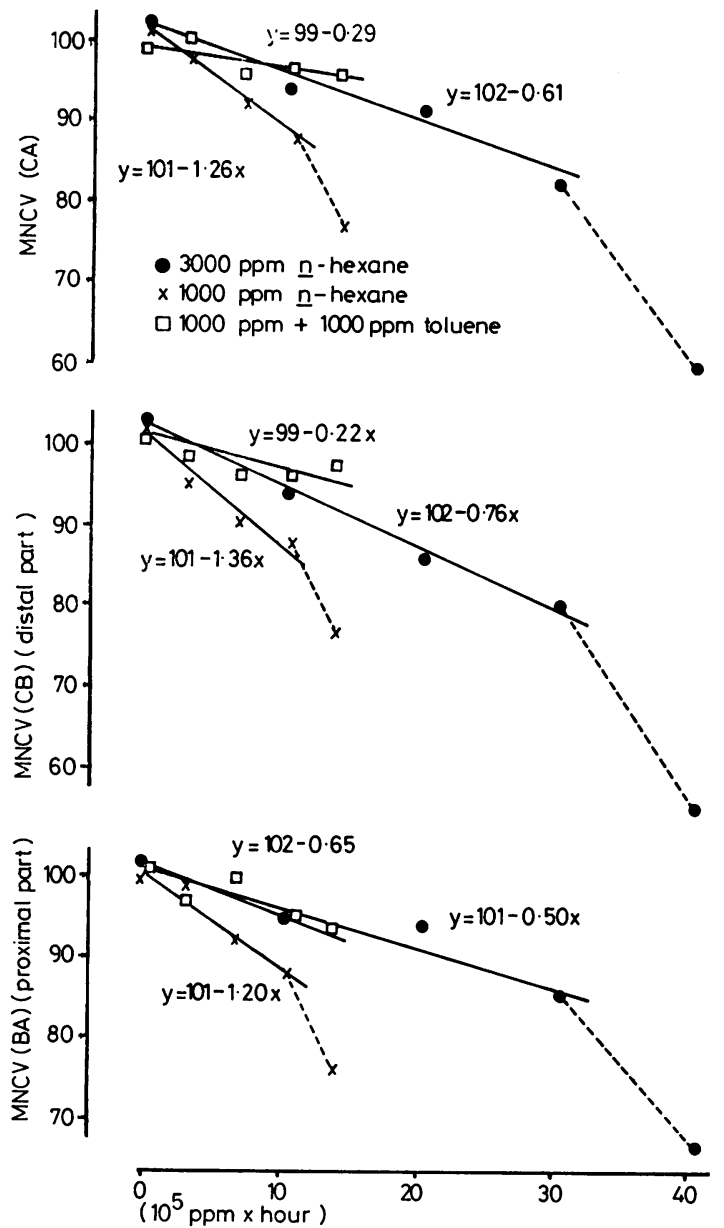

Iiig 7 Relations between dose of n-hexane $(\mathrm{ppm} \times \mathrm{hr})$ and effect (percentage of measured value per the control).

oxidation of $n$-hexane into neurotoxic substances thus reducing its neurotoxicity.

MEK has been shown experimentally to enhance the neurotoxicity of $n$-hexane ${ }^{5}$ and MBK (a metabolite of $n$-hexane), ${ }^{6} 15$ although not itself particularly neurotoxic. The exposure of MBK plus MEK is reported to increase blood MBK and 2,5-hexanedione concentrations in the rat and to enhance neurotoxicity by comparison with exposure to MBK alone. ${ }^{15} \mathrm{MBK}$ and 2,5-hexanedione, which are considered to be the main neurotoxic metabolites of $n$-hexane, are thought to act by inhibiting the glycolytic enzymes, glyceraldehyde-3-phosphate dehydrogenase and phosphofructokinase, and by reducing ATP levels in nerve tissue, thus disturbing energy transport in the nerve fibre. ${ }^{12}$ From these reports it may be inferred that toluene inhibits the metabolism of $n$-hexane to neurotoxic substances thus reducing its neurotoxicity, whereas MEK might inhibit the biotransformation of neurotoxic substances to others less toxic, thus enhancing the neurotoxicity of $n$-hexane and MBK. Although the problems of which metabolites of $n$-hexane are responsible for the neuropathy and of the mechanism of action are still being clarified, we consider it important from the viewpoint of industrial toxicology that the neurotoxicity of $n$-hexane may be easily modified by other solvents.

The relations between the total dose of $n$-hexane and the effects were linear in both $1000 \mathrm{ppm}$ and $3000 \mathrm{ppm} n$-hexane-alone exposure groups, with the exception of MNCVs after 16 weeks' exposure. The slopes of the regression lines of MCV were steeper than those of MNCVs until 12 weeks' exposure, but MNCVs dropped after 16 weeks' exposure in both $1000 \mathrm{ppm}$ and $3000 \mathrm{ppm} n$-hexane groups. These results suggest that the function of the efferent and afferent nerves might be impaired differently by $n$-hexane. The slopes of the regression lines in the $1000 \mathrm{ppm} n$-hexane group were steeper than those in the $3000 \mathrm{ppm} n$-hexane group, although the experimental conditions were almost the same in both experiments. This result implies that within a certain range the ratio of metabolised $n$-hexane to the inhaled dose might be less at the higher concentration than at the lower.

The petroleum refinery industry has developed rapidly in Japan in recent years, and has been providing a large amount of refined commercial hexane which contains a high percentage of $n$. hexane, and many cases of $n$-hexane polyneuropathy have been reported in the past ten or so years. ${ }^{11617}$ $\mathrm{n}$-Hexane has been used for a long time as one of the major ingredients in petroleum solvents, and the recent outbreak of $n$-hexane polyneuropathy may be due to the rapid increase of the consumption of refined commercial hexane and to the great increase in the $n$-hexane content of solvents, although it has been reported that the neurotoxicity of $n$-hexane may be enhanced by adding MEK to solvents containing $n$-hexane. ${ }^{5}$

We gratefully acknowledge the advice of Professors Toshi Inoue and Hideo Ohta. The study was supported by grants from the Ministry of Education, Japan, and from the Chiyoda Mutual Life Foundation.

\section{References}

${ }^{1}$ Inoue $\mathrm{T}$, Takeuchi $\mathrm{Y}$, Takeuchi S, et al. A health survey on vinyl sandal manufacturers with high incidence of 
"n-hexane" intoxication. Jap J Ind Health 1970;12: 73-84. (In Japanese with English abstract.)

${ }^{2}$ Herskowitz A, Ishii N, Schaumburg HH. n-Hexane neuropathy-a syndrome occurring as a result of industrial exposure. $N$ Engl J Med 1971;285:82-5.

${ }^{3}$ Spencer PS, Bishoff MC, Schaumburg HH. On the specific molecular configuration of neurotoxic aliphatic hexacarbon compounds causing central-peripheral distal axonopathy. Toxicol Appl Pharmacol 1978;44: 17-28.

${ }^{4}$ Suzuki T, Shimbo S, Nishitani H, Oga T, Imamura T, Ikeda M. Muscular atrophy due to glue sniffing. Internationales Archiv fur Arbeitsmedizin 1974;33:115-23.

${ }^{5}$ Altenkirch H, Stoltenburg G, Wagner HM. Experimental studies on hydrocarbon neuropathies induced by methyl-ethyl-ketone (MEK). J Neurol 1978;219:159-70.

${ }^{6}$ Saida K, Mendell JR, Weiss HS. Peripheral nerve changes induced by methyl $n$-butyl ketone and potentiation by methyl ethyl ketone. J Neuropathol Exp Neurol 1976;35: 207-25.

${ }^{7}$ Maeda K. Gas chambers for the exposure of animals to organic solvents. Jap J Ind Health 1968;10:427-32. (In Japanese with English abstract.)

${ }^{8}$ Ono Y, Takeuchi Y, Hisanaga N. Studies on the method of measuring nerve conduction velocity in rat's tail and on the comparative toxicity of $n$-hexane, methyl $n$-butyl ketone, and 2,5-hexanedione. Jap J Ind Health 1979; 21 :528-38. (In Japanese with English abstract.)

- Takeuchi Y, Ono Y, Hisanaga N. A comparative study on neurotoxicity of $n$-pentane, $n$-hexane and $n$-heptane; electrophysiological and morphological changes of peripheral nerves and muscles of rats. Br JInd Med 1980; 37:241-7.

${ }^{10}$ Schaumburg HH, Spencer PS. Degeneration in central and peripheral nervous systems produced by pure $n$-hexane. Brain 1976;99:183-92.

${ }^{11}$ Couri D, Abdel-Rahman MS, Hetland LB. Biotransformation of $n$-hexane and methyl $n$-butyl ketone in guinea pig and mice. Am Ind Hyg Assoc J 1978;39:295-300.

12 Spencer PS, Sabri MI. Methyl $n$-butyl ketone, carbon disulfide and acrylamide; putative mechanisms of neurotoxic damage. Abstracts of International Congress on Neurotoxicology, Varese, Italy. Oxford: Pergamon Press Ltd, 1979:134.

${ }^{13}$ Ikeda M. Reciprocal metabolic inhibition of toluene and trichloroethylene in vivo and in vitro. Internationales Archives fur Arbeitsmedizin 1974;33:125-30.

14 Ikeda M, Hirayama N. Alleviation of benzene leukopenia in rats simultaneously exposed to toluene. Arh Hig Rada Toksikol 1979;30 suppl:477-81.

${ }^{15}$ Abdel-Rahman MS, Hetland LB, Couri D. Toxicity and metabolisn of methyl n-butyl ketone. Am Ind Hyg Assoc J 1976;37:95-102.

${ }^{16}$ Yamada S. Polyneuritis in workers exposed to $n$-hexane, its cause and symptoms. Jap J Ind Health 1967;9:651-9. (In Japanese with English abstract.)

17 Yamamura Y. n-Hexane polyneuropathy. Folia Psychiatr Neurol Jpn 1969;23:45-57. 